La

Révolution

française

\section{La Révolution française}

Cahiers de l'Institut d'histoire de la Révolution française

$22 \mid 2022$

L'étranger en révolution(s)

\title{
Quand l'étranger est le Français qui voyage
}

Voyager en Italie en temps de révolution (années 1780-années 1800)

When the foreigner is the Frenchman who travels: Travelling in times of revolution

\section{Gilles Bertrand}

\section{OpenEdition \\ Journals}

Édition électronique

URL : https://journals.openedition.org//rf/6114

DOI : $10.4000 /$ Irf.6114

ISSN : 2105-2557

Éditeur

IHMC - Institut d'histoire moderne et contemporaine (UMR 8066)

Référence électronique

Gilles Bertrand, «Quand l'étranger est le Français qui voyage », La Révolution française [En ligne], 22 |

2022, mis en ligne le 20 janvier 2022, consulté le 24 janvier 2022. URL : http://

journals.openedition.org/lrf/6114; DOI : https://doi.org/10.4000/Irf.6114

Ce document a été généré automatiquement le 24 janvier 2022.

(c) La Révolution française 


\title{
Quand l'étranger est le Français qui voyage
}

\author{
Voyager en Italie en temps de révolution (années 1780-années 1800) \\ When the foreigner is the Frenchman who travels: Travelling in times of \\ revolution
}

Gilles Bertrand

1 Tandis que les voyages bénéficiaient de moyens techniques qui les rendaient plus aisés et rapides dans les dernières décennies du XVIII ${ }^{\mathrm{e}}$ siècle, phénomène qui s'accentua au $\mathrm{XIX}^{\mathrm{e}}$ siècle avec l'usage de la vapeur, l'expérience du séjour à l'étranger devint paradoxalement de moins en moins nécessaire dans les processus d'apprentissage des élites françaises. En dépit des listes dressées par Berchtold et Volney entre 1789 et $1795^{1}$ pour donner aux enquêtes dans des pays étrangers une plus grande efficacité, les velléités d'intégrer dans le cursus des meilleurs élèves des écoles centrales la connaissance du département où ils vivaient par un voyage annuel révèle qu'il n'était plus sous le Directoire et le Consulat conseillé aux jeunes gens de sortir de France. En rupture avec les conseils d'aller compléter leur formation à l'étranger donnés aux membres des élites de toutes nations par les arts de voyager de l'époque moderne - de Theodor Zwinger ou Juste Lipse à Francis Bacon, de James Howell ou Maximilien Misson à Richard Hurd -, on constate, avec Gábor Gelléri, qu’à la fin du XviII e siècle «le besoin perçu de l'expérience de l'étranger afin de remplir un rôle dans la société » a en France quasiment disparu pour les jeunes gens au profit d'une apologie des voyages nationaux : «La priorité donnée à la connaissance de la France elle-même, une fois de plus, est un processus qui a commencé à la fin du xvIII siècle et qui s'est considérablement accru à l'époque de la Révolution ${ }^{2}$ ». Pourtant, au même moment, la contrainte de l'exil vécue par les émigrés autant que les exigences des métiers de soldat ou d'administrateur chargés de répandre les principes et idées de la Révolution ont amené de nombreux Français à accomplir hors de France des types de déplacements qui les ont plus qu'auparavant identifiés comme « Français » aux yeux de leurs voisins européens ${ }^{3}$. Désormais distincts du Grand Tour, les cadres du voyage accompli en temps de Révolution ont ainsi amené ceux qui quittaient la France à forger au contact des 
populations étrangères -italiennes notamment - de nouvelles identités qui n'étaient plus celles des sujets cosmopolites de l'Europe d'Ancien Régime. Le cas de l'Italie, destination privilégiée du Grand Tour, constitue une bonne occasion d'évaluer l'impact qu'eurent la volonté de fuir ou l'esprit de mission civique sur la façon dont les voyageurs français furent amenés à vivre leur étrangeté, notamment ceux jusque-là habitués à ce que la langue qu'ils parlaient leur ouvre de nombreuses portes. C'est cette construction de soi dans un contexte à de nombreux égards inattendu et singulier que nous allons interroger : en quoi rompit-elle avec le passé et quels horizons ouvrit-elle? Pour répondre à cette question, nous nous demanderons d'abord comment les Français partis en voyage forcé ou volontaire vers l'Italie firent à partir de la Révolution française émerger des figures inédites de l'étranger, qu'ils contribuèrent en retour à façonner en naviguant entre trois paramètres, ceux de la nation en marche, du dépaysement et de la familiarité. Nous questionnerons ensuite la manière dont les pratiques de surveillance et de classement au passage des frontières avec les États italiens ou à l'entrée dans les villes participèrent à l'élaboration d'un statut plus politique de l'étranger, qui précipita le passage de la qualité de straniero ou de forestiero à celle d'esule, de rifugiato ou d'emigrato, voire tout simplement de francese, "Français ». Enfin, nous tenterons de décrire l'épreuve inédite d'étrangement que vécurent les Français présents en Italie aux époques révolutionnaire et impériale, générant de nouveaux types de classement des individus en même temps que des formes nouvelles de souffrance et d'appréhension de l'autre.

\section{Façonner une nouvelle figure de l'étranger dans un pays pourtant si familier}

2 Une longue tradition du voyage a amené les Français cultivés ou éduqués à passer au XVIII ${ }^{e}$ siècle de la France vers la Savoie, le Piémont, la Ligurie ou la Toscane et, de là, dans les autres États italiens pour quelques mois ou années sans avoir véritablement conscience de se rendre en terre étrangère. La Révolution de 1789 installa une forme de citoyenneté républicaine qui prolongeait le travail de sape par lequel les penseurs des Lumières avaient fini par opposer à la citoyenneté " absolutiste ", appuyée sur le droit d'aubaine séparant les naturels des étrangers, un modèle de citoyenneté universelle ${ }^{4}$. Or, l'absence d'adhésion aux principes politiques de la Révolution transforma soudain de nombreux anciens praticiens du Grand Tour en contre-révolutionnaires, amenés à perdre de fait leur citoyenneté en raison de leur "traitrise " ${ }^{5}$. Cette perte était concrétisée par une émigration qui à leurs yeux était souvent le seul moyen de sauver une identité déchirée entre la fidélité au roi et l'attachement à une terre natale, alors même que les arts de voyager s'étaient mis depuis les années 1770 à promouvoir, à l'instar de Diderot, l'idée d'utilité de la patrie en lieu et place d'un processus d'éducation personnelle. Dans un monde bouleversé où l'on pouvait bénéficier de l'accès à la citoyenneté en partageant des idéaux révolutionnaires et, inversement, devenir étranger, exclu de la nation, proscrit dans son propre pays, les aristocrates voyageurs des années révolutionnaires virent le sens de leur voyage changer brutalement de signification. En France et ailleurs, ils furent perçus et traités comme étrangers en fonction de critères qu'ils n'avaient pas connus auparavant.

3 Certes, sous l'Ancien Régime, quand le séjour à l'étranger se prolongeait, le droit d'aubaine et l'hypothèse d'une naturalisation avaient depuis longtemps créé des cadres 
contraignants, mais cela ne concernait précisément que les résidents étrangers de longue durée ${ }^{6}$. L'utopie éclairée de la liberté d'aller et de venir avait au contraire installé au cours du XVIII ${ }^{e}$ siècle une représentation cosmopolite favorable à l'accueil de l'étranger, dont se fait écho la définition qu'en offre Jaucourt, guidé par la tradition protestante de sa famille, dans l'Encyclopédie en 1756 :

ÉTRANGER, s. m. (Droit polit.) celui qui est né sous une autre domination \& dans un autre pays que le pays dans lequel il se trouve. [...] Personne n'ignore que rien ne contribue davantage à la grandeur, la puissance \& la prospérité d'un état, que l'accès libre qu'il accorde aux étrangers de venir s'y habituer, le soin qu'il prend de les attirer, \& de les fixer par tous les moyens les plus propres à y réussir. Les Provinces-Unies ont fait l'heureuse expérience de cette sage conduite.

Un rapide examen, ici épargné au lecteur, des définitions du mot « étranger » dans les dictionnaires en langue française ne révèle que de faibles glissements entre 1690 (Dictionnaire universel de Furetière) et 1798 (cinquième édition du Dictionnaire de l'Académie). L'« étranger " reste d'un siècle à l'autre celui qui est "d'un pays éloigné " ou "d'une autre nation", "né sous une autre domination » et que l'on refuse par divers procédés de considérer comme membre à part entière de la communauté d'accueil, ce qui sous l'Ancien Régime justifiait notamment le droit d'aubaine qui limitait pour l'étranger le pouvoir d'hériter ou de transmettre des biens. Les notions d'éloignement et d'altérité n'ont cessé en parallèle de justifier dans les mêmes dictionnaires un sens figuré s'appliquant à divers registres : «On dit figurément, qu'un homme est estranger dans sa famille, en son pays, en une science, quand il ne sçait point les affaires de sa maison, les nouvelles de son pays, les premiers principes d'une science $»^{7}$. L'étrangeté pouvait s'appliquer à des coutumes, à des lois, à une langue autant qu'à des produits du sol, à un climat, voire simplement à un "air étranger ». Ainsi, pour un voyageur du Grand Tour à l'époque des Lumières, la familiarité et la reconnaissance en terre éloignée se gagnaient-elles au prix d'un apprentissage. Tout fut à reconstruire en temps de Révolution, du fait des changements qui affectèrent à la fois le statut juridique et la représentation de soi du Français se déplaçant hors des frontières de son pays. Ce sont ces transformations qu'il nous faut mesurer en nous plaçant sur le registre de la perception par chaque individu de sa propre étrangeté et sur celui du travail opéré par les administrations des pays d'accueil, brutalement amenées à dresser de nouvelles barrières et réglementations pour mieux contrôler les flux d'étrangers.

5 Si notre enquête sur les Français qui voyagèrent en Italie entre 1789 et les années 1800 entend mettre au premier plan la subjectivité des voyageurs et leurs processus d'étrangement, nous ne pouvons ignorer leur lien avec l'approche de l'étranger qui fut donnée dans les Constitutions qui se sont succédées en France. Celle de l'an I introduisit la notion d'engagement politique pour justifier d'abolir la barrière qui séparait l'étranger du citoyen en proclamant : « Tout étranger âgé de vingt et un ans accomplis, qui, domicilié en France depuis une année, y vit de son travail, ou acquiert une propriété, ou épouse une Française, ou adopte un enfant, ou nourrit un vieillard; tout étranger enfin, qui sera jugé par le Corps législatif avoir bien mérité de l'humanité [c'est nous qui soulignons], est admis à l'exercice des droits de citoyen français $»^{8}$. Mais cette problématique de l'invention de la citoyenneté et de l'exclusion des non-citoyens par rapport à une "société nationale » a été largement traitée par divers historiens dans les années 1990, dont Rogers Brubaker, Olivier Le Cour Grandmaison, Sophie Wahnich et Michael Rapport ${ }^{9}$. Ce qui va nous retenir ici à travers le cas des présences françaises 
en Italie sera de chercher à comprendre comment la sensation d'étrangeté éprouvée loin de chez soi renvoie à un état d'âme du voyageur. Délaissant les analyses sur la fabrique du couple citoyenneté/étranger à l'intérieur d'un espace national, nous nous demanderons ce que nous enseignent les cahiers de voyage, journaux et correspondances comportant des réflexions personnelles de Français confrontés à l'étrangeté par le fait même de leur déplacement. En nous appuyant sur quelques sources utilisées à l'occasion de travaux antérieurs, mais également sur les fonds des archives d'État de Turin concernant les émigrés venus de France entre 1789 et 1798 et sur le récit manuscrit du marquis de Pons récemment acheté par la Bibliothèque municipale de Grenoble, où l'auteur, sans doute diplomate, mais sur lequel on est peu informé, narre un voyage d'agrément en Italie du 5 octobre 1790 au 26 juillet 1791, qu'apprenons-nous des sentiments de ceux qui traversèrent la France et se rendirent en Italie, au prix d'un éloignement vécu de façon inédite par rapport à leur terre natale?

6 L'expérience de l'étrangeté vécue en temps de Révolution par les Français qui se rendirent en Italie ne peut se comprendre sans tenir compte des logiques d'appropriation d'un espace national qui, face au cosmopolitisme, avaient progressivement gagné l'esprit des voyageurs français depuis les années 1780 . Les curieux, les savants et les agents de l'administration furent encouragés à quadriller le territoire national en inventoriant les richesses des diverses provinces et ainsi à s'identifier peu à peu à leur patrie grâce à des enquêtes de terrain ${ }^{10}$. Il fallait apprivoiser les zones d'ombre du sol national pour les arracher à une étrangeté assimilable au monde sauvage à « civiliser ». Des Français visités par les commissaires de l'an II dans les campagnes à l'enfant sauvage de 1'Aveyron transféré à Paris en 1800, ce sont partout des formes d'altérité qu'il s'agissait de réduire au cœur de la France en promouvant un idéal républicain progressiste ${ }^{11}$. Les émigrés, porteurs d'une vision conservatrice de la société, pouvaient-ils dans ces conditions encore manifester la supériorité d'une civilisation ou étaient-ils destinés à devenir non certes des ignorants ou des sauvages, mais du moins des étrangers par force exclus du corps social et politique de la nation?

7 Une telle mise en état d'étrangeté ne fut pas le lot des seuls émigrés. Sans se confondre avec les exils de parlementaires qui, sous l'Ancien Régime, se retiraient par ordre du roi dans un château éloigné de la cour, mais connu de l'exilée ${ }^{12}$, les girondins exilés après la journée du 2 juin 1793 s'étaient transformés en étrangers dans leur patrie, une fois contraints d'errer à travers le territoire national ${ }^{13}$. C'est aussi une forme d'étrangeté à connotation sociale que le marquis de Pons ressentit à Roanne au retour d'Italie en juillet 1791 quand il constata le fossé entre seigneurs et paysans, «gens du bas peuple et de mauvaise tête » obligeant les seigneurs à rester seuls " parce que dans ce moment les paisants ne trouvoient pas bon que les seigneurs allasent (sic) les uns chez les autres parce qu'ils soupsconoient (sic) quoique fort mal a propos qu'ils ne se reunissoient que pour caballer et pour tacher de faire une contrerévolution $»^{14}$. Il n'est pas sûr que ce sentiment d'étrangeté éprouvé au sein de leur patrie était de même nature que celui ressenti en rencontrant les Suisses dans leur montagne ou bien des Vénitiens, des Romains ou des Napolitains au cours de leur voyage en Italie. Au contraire, en-dehors des formes de dépaysement violent, c'est bien l'expérience d'une familiarité que les Français continuèrent, au début de la Révolution, à rechercher à l'étranger, dans des espaces ne présentant comme Turin qu'un léger décalage par rapport à ceux qui leur étaient habituels. Tout au plus l'absence de bains dans les villes d'Italie révéla-t-elle à 
Pons en 1790 qu'il était dans un pays étranger, mais sous la forme d'un détail accessoire : "le baigneur me surprit beaucoup en me disant [...] qu'en général on se baignoit fort peu à Turin et que c'etoit la meme chose dans toutes les villes d'Italie $»^{15}$.

De son côté, le pittoresque de la Suisse et des montagnes de Savoie désignait depuis la fin des années 1770 pour les élites européennes un espace à la fois proche et lointain, déroutant par rapport aux villes de France, mais de plus en plus apprivoisé depuis que, autour de 1750, les montagnes de Savoie avaient commencé à devenir attractives aux yeux des Britanniques. Ainsi, dans les premières années de la Révolution, des émigrés comme le prince de Condé et son petit-fils le duc d'Enghien rivalisèrent-ils d'enthousiasme face au spectacle qu'offraient certains paysages italiens. Le prince de Condé s'enivra à l'été 1789 du « coup d'œil le plus enchanteur dont on puisse se faire une idée " depuis le palais Doria à Gênes, avant que son voyage ne se transforme en exil, tant du point de vue politique que sentimental, à partir du mois d'octobre 1789 à Turin $^{16}$. Cette quête de jouissances et de connaissances dans un univers au fond familier relève de l'esprit du Grand Tour et se retrouve chez le marquis de Pons, qui décrit les paysages de plus en plus «intéressants " au fur et à mesure qu'il traverse la Savoie à l'automne 1790, le chemin «tres pitoresque (sic)» en Maurienne qui «ressemble beaucoup à la Suisse » et « deux cascades fort belles » en descendant à La Novalese vers Suse $^{17}$. Il s'agissait bien alors pour le voyageur cosmopolite de trouver en terre étrangère ce qu'il en attendait, c'est-à-dire un univers qui ne le surprenait qu'à l'intérieur d'un programme dont il avait la maîtrise.

9 Certes, en même temps qu'il se divertissait, l'étranger en voyage continuait d'être confronté à de classiques sources d'inconfort qui, en l'irritant, l'amenaient à juger de la distance séparant de son espace familier les contrées parcourues. Une langue étrangère pouvait indisposer le voyageur, comme l'italien pour l'émigré Anot se rendant à Malte en 1795 : «Il me tarde d'être rendu à ma destination; car quel ennui de voyager dans un pays dont on n'entend pas la langue ! En vain parlè-je François, Latin, Hollandois ou Allemand, personne ne me comprend ${ }^{18}$. De façon convenue, c'est l'état «detestable » des auberges «ou on est horriblement » qui obsède le marquis de Pons tandis qu'il se rend de Paris en Italie $^{19}$. Chez ce même voyageur, la gamme des situations d'étrangement comprend encore en ce temps de Révolution la lamentation sans cesse répétée au $\mathrm{XVIII}^{\mathrm{e}}$ siècle sur les coûts de la poste, les contraintes de la douane ou la variété des monnaies :

Ce changement de payement par la poste est insuportable (sic) pour les voyageurs, a la ville ou il dejeune, il la paye un prix different de celuy ou il dine, ou il soupe, tantost c'est argent de Genes, tantost argent de Piemont tantost argent de Milan, il y a de quoy impattienter l'homme le plus phlegmatique, il gemit d'estre obligé de passer sur le territoire de tant de differents paüs dont toutes les regles sont aussi differentes ${ }^{20}$.

Vouloir l'uniformisation des monnaies, des prix et des mesures, tout comme dénoncer ceux qui « font leur possible pour tromper encore sur le prix des monoyes ${ }^{21}$, ce n'est pas forcément être révolutionnaire, mais c'est recourir à un stéréotype de la friponnerie et faire perdurer un préjugé véhiculé par de nombreux voyageurs français au XVIII ${ }^{\mathrm{e}}$ siècle, avec pour résultat d'opposer l'étrangeté italienne à une certaine idée de soi et de sa patrie. C'est à peine si le confort du « déjà vu » parvient à vaincre l'effet de cet enchaînement de désagréments. En revoyant au cours de son voyage en Italie de 1790 des lieux déjà fréquentés lors d'un précédent voyage, notre même témoin, le marquis de Pons, atténue la force des risques que présente l'étrangeté. Un dîner à La 
Novalese est jugé «moins mauvais que celuy que j'avois eu quelques années auparavant ", tandis qu'à Turin «j'allai revoir avec plaisir le palais du Roi, l'université, et les memes objets qui avoient satisfait ma curiosité a mon premier voyage ${ }^{22}$. L'impact du dépaysement se dissout dans l'acte de mémorisation et de reconnaissance des lieux. Si dépaysement il y a, il peut demeurer agréable et familier et les rencontres avec des personnes du même monde assurent une continuité dans les pratiques de sociabilité aristocratique. De même que le voyageur Pons goûte aux plaisirs de la société dans chacune des villes où il fait étape, de même les émigrés trouvaient, dans les premières années de la Révolution, à Turin, Parme ou Rome un accueil de l'ambassadeur du roi de France qui leur permettait de ne pas se croire encore totalement « étrangers » sur le sol italien. Il s'y ajoutait pour les émigrés la sensation de soulagement en arrivant dans un pays qui n'avait pas connu les bouleversements de la Révolution : «Je ne chercherai pas à décrire, avoue Marcillac en se rappelant le mois de mars 1791, les idées enchanteresses qui s'emparèrent de mon imagination lorsque je touchai le territoire piémontais, et surtout lorsqu'en arrivant à Chambéry j'aperçus des cocardes blanches $»^{23}$. Dans le même ordre d'idées, Vitrolles dit de la Suisse, où il séjourna au début de 1794, qu'alors elle "était le pays hospitalier par excellence ${ }^{24}$. Sans être propre au temps de Révolution, ce type d'expression prouve que les acquis du cosmopolitisme permettaient encore d'éviter de se sentir étranger en voyage, au moins pour un temps.

\section{Vers un nouveau statut juridique : surveillance, passages de frontières et usages du passeport}

11 La mise à mal du cosmopolitisme se manifeste à travers l'affirmation de frontières nationales qui entravèrent la possibilité pour les plus aisés de se sentir chez eux partout en Europe. Les barrières étaient présentes en France dès le début de la Révolution, mais elles se renforcèrent au gré d'une histoire chaotique des lois entre 1789 et 1793 . Dès octobre 1790, Pons, notre voyageur « témoin », évoque la menace des fouilles pratiquées partout sur le territoire :

On m'avoit asseuré (sic) a Moulins que Mr. leveque [ =l'évêque ?] de St. Pons y avoit eté mis en chemise pour voir s'il n'y avoit point de papiers interessants[,] si ses passeports etoient bien en regle, et s'il n'avoit pas baucoup (sic) d'or avec luy. [...] Pour aller aux Echelles nous passames au Pont de Beauvoisin ou on sort de France et nous n'y epprouvames (sic) pas plus de difficultés que à Bourgoin. On fit semblant de vouloir nous fouiller ${ }^{25}$.

12 Pour le Français qui voyageait hors de France et se rendait en Italie, des limites drastiques furent également posées par les contrôles que les États italiens installèrent à leur tour, autant à l'encontre des émigrés que des éventuels propagateurs des idéaux révolutionnaires. À l'âge des lettres de recommandation succéda celui de la surveillance policière qui n'épargna personne. Ce choc bureaucratique se manifesta en Toscane comme en France ou dans l'Empire autrichien, ainsi que l'ont montré Vincent Denis, Carlo Mangio et Alfredo Viggiano ${ }^{26}$. Mais Valentina Dal Cin a aussi mis en lumière la persistante incertitude des appartenances nationales en évoquant le cas d'un émigré français mort au début de 1795 alors qu'il séjournait à Venise: à quelle patrie appartenait-il ? Relevait-il de la souveraineté des Bourbons où qu'ils règnent, comme l'indiqua l'agent consulaire espagnol qui entendait statuer sur son héritage, ou bien continuait-il d'appartenir à la patrie française qui l'avait pourtant rejeté du corps 
national ${ }^{27}$ ? S'opposant aux visées du représentant de l'Espagne Campos sur la succession du comte d'Amagé, son homologue français Lallement développa à cette occasion une théorie de la légitimité française sur laquelle V. Dal Cin conclut :

Bien qu'apparemment convaincant, l'argument de Lallement omettait le fait que, puisque les émigrants étaient déjà décédés civilement, leurs biens n'auraient certainement pas été remis à leurs familles, mais plutôt à l'État. De plus, de manière tout à fait contradictoire, le même envoyé qui, quelques mois plus tard, devant les autorités vénitiennes, allait distinguer les émigrés des « vrais Français ", s'acharna en l'occurrence à les confondre. De son point de vue, ils étaient toujours soumis à la représentation diplomatique française, car le fait d'être favorables à la monarchie et de se ranger politiquement du côté de l'Espagne n'en faisait pas ipso facto des sujets espagnols ${ }^{28}$.

13 Voilà qui nous rappelle qu'au début de la Révolution n'existait pas de définition explicite du Français. La nationalité restait mal assise, elle n'était pas encore devenue un droit attaché à la personne, puisque, comme le précise Patrick Weil, il fallut pour cela attendre le Code civil en $1803^{29}$. Aux yeux des puissances étrangères à la France, la figure du Français incarne dans les années 1790 la perspective d'exportation du désordre révolutionnaire, suscitant une traque ambivalente dans les États italiens au cours des années 1790. En étant associés à la Révolution, quel que fût leur positionnement politique, les Français faisaient peur et devenaient par-là plus étrangers - car plus menaçants - qu'ils ne l'étaient au temps où dominait le cosmopolitisme. Dans le cas vénitien, qui n'est pas isolé en Italie, s'opéra de la sorte une sélection entre les étrangers acceptables de l'Europe d'Ancien Régime - Britanniques, Allemands, Scandinaves, Russes - et les Français dont il convenait de se défier, fussentils émigrés. Les Piémontais, Génois et Suisses, ressortissants de nations limitrophes de la France, devaient être surveillés de manière spécifique ${ }^{30}$. Tous ces Français ou personnes provenant de territoires limitrophes devenaient ce que les mises en fiche des hôteliers et agents de l'administration en faisaient: des noms sur des listes interminables.

14 Certes, des correspondances conservées à Turin sur l'aide à apporter aux émigrés à partir de 1792 fabriquèrent à leur tour une étrangeté à deux vitesses : celle des sujets étrangers que l'on pouvait accueillir et protéger et celle de ceux qu'il fallait exclure et refouler ${ }^{31}$. En vertu du Manifesto senatorio du 29 septembre 1792, et même si les autorités à ce stade ne recoururent pas à la force armée, de nombreuses catégories de Français furent soumises, dans les semaines suivantes, à une expulsion immédiate, tels les domestiques hommes et tous les sujets bien portants non-chargés de famille ou ne bénéficiant pas de la faveur royale ${ }^{32}$. La distinction fut particulièrement nette jusqu'en 1795. Des lettres étaient envoyées par le Secrétariat d'État aux affaires intérieures, dirigé par le comte Graneri, à des autorités civiles, militaires ou religieuses locales afin qu'elles signifient aux émigrés français non pourvus de passeport une fin d'autorisation de séjour, refoulent promptement des suspects ou au contraire fassent état de places à assigner aux ecclésiastiques dans certains établissements religieux; d'autres lettres étaient remises aux émigrés pour leur accorder un prolongement de subsides, les autoriser à changer de domicile en Piémont ou leur rappeler que leur permission de séjourner avait pris fin. Ces dossiers montrent comment l'administration piémontaise traita le statut d'étranger des Français en instaurant une série de gradations dans le contexte de l'urgence révolutionnaire. Bien qu'ils étaient tous considérés comme une menace par les autorités, une subtile dichotomie séparait les bons et les menaçants, les amis inscrits dans des réseaux familiaux et politiques familiers du pouvoir et les 
possibles ennemis s'infiltrant dans les territoires du roi de Sardaigne sans qu'on connaisse leurs réelles intentions. Les mêmes distinctions peu visibles étaient opérées par les gouvernements de Venise, Turin, Florence, Rome ou Naples à la fin du XVIII ${ }^{\mathrm{e}}$ siècle.

En 1789, l'évocation du passeport par les voyageurs n'était pas une nouveauté. Gilles Montègre a rappelé que les procédures de contrôle aux frontières des divers États italiens étaient perçues de façon variable par les Français tout au long du XVIII ${ }^{\mathrm{e}}$ siècle. Le passeport avant la Révolution, du moins en période de paix, visait cependant "moins à contrôler les déplacements qu'à faciliter au contraire la circulation au bénéfice de personnes ciblées $»^{33}$. De ce fait, il intégrait le voyageur à une sorte de communauté supranationale qui lui permettait d'échapper au sentiment d'étrangeté. Le poids des contrôles n'en était pas moins déjà vivement ressenti avant 1789, ainsi que le révèle l'impatience du botaniste Latapie à propos de ses expériences en Italie en 1775 :

Ces formalités ne font qu'arrêter les honnêtes gens, sans être fort utiles contre les mauvais sujets. Les princes devraient laisser à chacun son libre arbitre, en convenant entre eux de se rendre réciproquement les criminels réclamés qui abuseraient nécessairement de la facilité de passer en pays étranger ${ }^{34}$.

Divers travaux, dont ceux de Marco Meriggi, ont montré de quelle manière on passa à Naples, au milieu du XVIII ${ }^{e}$ siècle, à un contrôle étatique plus centralisé qui marginalisa les pratiques corporatistes et locales de contrôle des étrangers - ceux qu'on appelait en italien les forestieri et qui, pour les Vénitiens, commençaient dès Mestre ${ }^{35}$. Devenu une preuve administrative concrète et visible de la condition d'étranger, le passeport fut de plus en plus souvent évoqué par les voyageurs de la fin du XvIII siècle, comme en témoignent les observations d'Arthur Young en 1789 sur le passeport intérieur en France ou celles de Benjamin Constant se souvenant en 1807 de la liberté dont jouissaient les voyageurs à la fin de l'Ancien Régime ${ }^{36}$. Au début de la Révolution était pourtant en vigueur en France le passeport pour l'intérieur du pays. Le marquis de Pons en souligne entre octobre 1790 et juillet 1791 - donc avant son abolition - le caractère discriminant, propre à marquer d'un signe pouvant devenir infâmant l'individu qui se déplaçait dans le territoire national ou bien qui se rendait à l'étranger ou encore en revenait.

Lors de son voyage d'aller vers l'Italie en octobre 1790, la traversée de la France et le passage de la frontière aux Échelles ne posèrent pas problème à Pons, malgré les craintes qui l'avaient conduit à se doter de multiples lettres de recommandations afin d'assurer la tranquillité de son parcours :

On nous avoit fait beaucoup d'histoire et propres a nous persuader que nous ne saurions prendre trop de precautions pour applanir les difficultés que nous trouverions soit pour sortir soit pour passer notre or. [...] D'après cela je metois muni de baucoup (sic) de lettres pour ce lieu, et Mr. Emery president de l'assemblée nationalle (sic) m'avoit donné une lettre ostensible pour cette municipalité dont la conduitte ridiculle s'etoit fait meme connoitre a Paris, mais tout cela nous devint fort inutille, car nous n'eprouvons aucunes difficultés (sic). Sur le vu de nos passeports on nous laissa passer sans mot dire ${ }^{37}$.

En revanche, à son retour, quelques mois plus tard, Pons dénonçait le zèle des patriotes qui faisaient d'un Français un étranger même quand il était en train de rentrer dans sa patrie. Il s'attarde sur le malentendu qui gâcha son arrivée à Lyon en juillet 1791, parce qu'on l'avait pris pour un autre M. de Pons, auvergnat : 
J'appris a Lyon que l'on ne m'avoit fait toutes ces difficultés que parce que on me prit pour M. de Pons d'Auvergne, sur lequel il y avoit de mauvaises nottes. Ce fut aussi par cette meme raison qu'on ne voulut pas d'abord rafraichir mon passeport[.] Mais quand je m'eus fait connoistre on y consentit tout de suitte (sic) ${ }^{38}$. leitmotiv des journaux de voyage à l'époque révolutionnaire. L'épisode des tantes de Louis XVI bloquées à Arnay-le-Duc sur le chemin de l'Italie du 22 février au 3 mars 1791 en dépit de leur passeport a été souvent raconté comme un exemple de la contrainte pesant sur l'émigré en partance ${ }^{39}$. Le marquis de Bombelles se réjouit à la fin mai 1791 de s'être fait expédier « un passeport de courrier impérial sous le nom de M. de la Porte, passeport qui m'affranchira de toutes les tracasseries de la route et de tout le temps qu'on perd aux barrières $»^{40}$.

Si en France le passeport fut aboli le 3-4 septembre 1791 (décret du 14-15 septembre), il fut rétabli par la loi du $1^{\text {er }}$ février 1792 (décret du 28 mars) qui stipulait la demande d'une autorisation pour circuler dans le royaume comme pour en sortir. Après avoir été à nouveau supprimé les 8 et 19 septembre 1792, il fut une seconde fois rétabli les 6 et 26 février 1793, puis confirmé par le décret du 2 octobre 1795 (10 vendémiaire an 4) qui en codifia la matérialité. Mais les États italiens l'exigeaient eux aussi. En août 1795, l'émigré Anot qui avait quitté le 14 juillet Ratisbonne pour se rendre à Naples - où il ne put d'ailleurs pas davantage entrer qu'à Rome - vint voir à Venise le Nonce « pour avoir la liberté du passage sur les terres Ecclésiastiques[,] et ce ne fut pas sans difficulté que son Auditeur nous accorda ce que nous demandions ». Rome, répète-t-il plus loin, « étoit fermée aux étrangers qui n'avoient pas de permission formelle d'y aborder; et le Nonce à Venise ne nous avoit accordé que très difficilement le passage par Ferrare et Bologne $»^{41}$. Certes, le passeport permettait à l'étranger de passer la frontière, qu'elle soit interne ou externe à l'État, et de vaincre les difficultés induites par le seul fait de se déplacer, mais, dans la péninsule italienne, un Français l'obtenait plus aisément pour sortir que pour entrer dans un État.

La surveillance exercée dans les divers États italiens contribua, tout comme celle interne à la France, à catégoriser comme étranger d'un nouveau type le Français qui voyageait, en le faisant passer du statut de personne à accueillir ou protéger à celui de personne à surveiller ou expulser. À Turin, certains Français étaient tolérés parce qu'ils étaient infirmes, malades et impotents, mais le passeport de ceux qui devaient partir au plus vite en vertu du Manifesto senatorio du 29 septembre 1792 indiquait la route à suivre pour quitter les États du Roi, afin qu'ils ne puissent pas découvrir l'état des défenses savoyardes. Roberto Zaugg et Diego Carnevale ont montré comment, à Naples, les étrangers, Français en tête, firent l'objet de mises en listes ou d'une délivrance de cartes de sûretée ${ }^{42}$. Dans les registres de passeports à Florence ou dans les annotations des Inquisiteurs d'État et des Esecutori contro la bestemmia à Venise entre 1790 et 1797, les étrangers étaient classés selon leur patrie, leur rang et leur profession ou activité et, parfois, des feuilles séparaient les Français des étrangers "d'autres nations », ce qui permettait de mettre en évidence les premiers et de les stigmatiser ${ }^{43}$.

On peut prendre à témoin les archives sur Rome étudiées par Domenico Maione ${ }^{44}$. Celuici montre comment les marges de tolérance à l'égard des ecclésiastiques français présents dans la capitale varièrent au gré des processus de politisation de la citoyenneté et d'événements tels que la révolte du Trastevere du 25 février 1798 contre la république romaine à peine installée : cette dernière visa en priorité les Français qui avaient participé au mouvement, à savoir les prêtres, contraints dès le 27 février de se

La Révolution française, 22 | 2022 
déclarer dans les 24 heures devant un fonctionnaire romain en déclinant leur âge, leur lieu de résidence, leur activité et la raison de leur venue à Rome, avant que l'on ne réduise en mai 1798 la libre circulation et les autorisations à rester sur place. Dans le même temps, pourtant, un processus d'intégration des curés de paroisse au sein de l'échiquier administratif républicain témoignait du souci d'utiliser le potentiel du clergé pour mieux organiser le contrôle de l'ordre nouveau - mais en extirpant les risques de subversion contre-révolutionnaire que pouvait recéler l'élément étranger. Dans le sillage de la décision du 11 mai 1798 allait être décrétée, dès août 1798, l'expulsion sous 24 heures de Rome et sous cinq jours des territoires de la République de tous ceux qui n'auraient pas acquis cette nouvelle forme de citoyenneté romaine traduite dans l'obtention d'une carte de sûreté (carta di sicurezza). Celle-ci définissait, par exclusion, le statut d'étranger en fonction de l'adhésion ou non à la république.

\section{Processus et statuts de l'étrangement, sur fond d'une nouvelle sensibilité}

Les documents déjà évoqués à Turin nous aident à construire une typologie des processus de mise en situation d'étrangeté des Français. En effet, pour les autorités piémontaises, à partir de 1792, il y avait des Français acceptables : ils l'étaient pour leur lien avec la dynastie ou leurs alliances familiales en Piémont, ou bien ils méritaient la compassion soit en raison de leur jeunesse, d'un handicap ou d'une maladie ou, pour les femmes, d'une grossesse, soit enfin, et de plus en plus, du fait de leur condition ecclésiastique et, parmi les prêtres et les moines, en raison de leur dignité ou de leur état de santé. Face à ces Français acceptés, fût-ce provisoirement, il en existait d'autres dont il fallait se séparer. Parmi ces derniers, certains étaient clairement considérés comme menaçants et à renvoyer au plus vite, mais une autre catégorie, la plus importante, était constituée d'individus souvent de bonne famille ou auxquels on ne reprochait rien. Leur seule « faute » était de ne pas avoir résidé en Piémont avant la fin de l'année 1788. Même s'ils n'apparaissaient guère comme dangereux, ces derniers étaient à expulser en tant que Français, c'est-à-dire parce que le royaume de Sardaigne était en guerre avec la France, après avoir perdu en novembre 1792 la Savoie, puis, en janvier 1793, le comté de Nice. Le Français était par définition l'autre, celui qui pouvait informer l'ennemi et l'aider à anéantir le royaume. Tout comme à Venise, des enquêtes étaient d'ailleurs menées par le secrétariat aux Affaires intérieures à Turin pour démasquer les fausses identités de Français qui se faisaient passer pour des sujets d'autres nations.

À l'autre bout de la chaîne, c'est-à-dire du côté des Français tolérés ou refoulés, une ample palette d'individus se profile. Les populations mobiles de Français séjournant d'une ville italienne à l'autre sous la Révolution se composent de nobles et de négociants, de membres du clergé, d'officiers et de propriétaires, parfois d'artisans ou d'artistes (peintres, danseurs ou acteurs). À la lecture des mémoires d'émigrés ou de leurs correspondances comme à celle des annotations des Inquisiteurs d'État à Venise, on voit se profiler une société française décalée, qui tend à vivre dans un milieu clos et à se laisser gagner par la nostalgie d'un monde perdu ${ }^{45}$. Il conviendrait d'ailleurs d'approfondir notre connaissance des milieux de l'émigration en Italie en nous tournant plus qu'on ne l'a fait jusqu'ici sur la condition qui fut celle des femmes, par un croisement des mémoires et correspondances avec des sources permettant de saisir un 
repli sur les arts de la table ou le marché des broderies et dentelles. Il arriva aussi que des émigrés français créent en Italie sous la Révolution de véritables entreprises, à l'instar du plus fameux d'entre eux, Charles Albert de Moré de Pontgibaud (1754-1824), qui à Trieste se transforma de noble de l'Ancien Régime en animateur d'une compagnie commerciale prospère et banquier de l'émigration de 1796 à $1815^{46}$.

À côté de ces cas exceptionnels de reconversion, il y eut chez les émigrés une souffrance de la mise en état d'étrangeté. Ceux-ci se retrouvèrent tout à coup apatrides ou, à tout le moins, étrangers à leur patrie, obligés de se construire un statut d'exilé là où ils avaient jusqu'alors été hors de France des étrangers cosmopolites, diplomates ou voyageurs libres de se sentir partout chez eux. La correspondance de Bernis, chargé d'affaires du roi de France à Rome, avec Flavigny, son homologue ambassadeur à Parme, montre comment certains Français en voyage avaient conscience du fait d'être devenus des étrangers à leur pays entre 1789 et 1792. Pour Bernis, les "émigrants " constituaient une catégorie de personnes distincte des autres étrangers venus du reste de l'Europe : «Cette incertitude m'a fait conserver une partie de ma maigre que je suis résolue de congédier, mais ma salle à manger n'est plus un réfectoire et mes assemblées ont été suspendues jusqu'à l'arrivée de nos émigrants et des autres étrangers " (21 octobre 1789). Les émigrés eurent beau être encore parfois qualifiés jusqu'à la fin de 1791 par Flavigny ou Bernis de "voyageurs de marque", de "voyageuses" ou de "visiteurs »- ainsi étaient appelés le comte de Boisgelin et Loménie de Brienne le 2 mars $1790^{-}$, ils furent aussi dénommés dès la première vague de l'été 1789 " proscrits» (selon le mot de Flavigny en août 1789), "émigrants ", "réfugiés » ou " infortunés » quand affluèrent les prêtres en août-octobre 1792. C'était bien là leur conférer un nouveau statut d'étrangers ${ }^{47}$.

Le marquis de Bombelles se coupa de son pays quand il décida de lâcher son ambassade à Venise le $1^{\text {er }}$ janvier 1791, par désaccord avec la politique suivie à Paris. Son journal confirme au printemps 1791 des glissements dans la manière de désigner les Français, désormais distribués entre "bons" ou "mauvais»: «ils reviennent de Rome et promènent comme tant d'autres Français leur triste et inquiète activité » (30 avril 1791, à Vienne) ; « la crainte de la contagion apportée par les mauvais Français [...] les zélés Français [...] la saine partie de la nation » (15 mai 1791, à Fribourg) ; « tous les Français qui ne sont pas dans le sens de la Révolution [...] » (17 mai 1791, à Genève $)^{48}$. Mais dès le 3 août 1789, Bombelles s'était déjà placé en état d'étrangeté quand, quittant Versailles, il s'était exclamé : «J'ai enfin atteint aujourd'hui les terres de l'Empire, et il m'a fallu regarder comme un bonheur de m'éloigner de mon pays, de mes amis, heureux de me tirer de cette terre qui dévore ses habitants et de pouvoir embrasser ma femme et mes enfants sans craindre que de farouches compatriotes viennent m'arracher de ces bras chéris $»^{49}$. Son épouse n'en avait pas pour autant trouvé le paradis à Venise, ainsi qu'elle l'écrivait à la marquise de Raigecourt en octobre 1790: "Nous croyons absolument être dans un autre monde et nos causeries du soir pourroient s'intituler dialogues des morts ", «nous n'avons pas le cœur fort gai », «mon cœur d'aucun côté n'est disposé à la joie $»^{50}$.

Cette tristesse de l'exil devenu absence au monde déboucha chez une centaine de Français signalés à Brescia entre août 1794 et février 1795 sur l'impossibilité de savoir où aller. Dans une thèse récente, Carlo Bazzani précise à leur sujet : «S'il est vrai que beaucoup visaient Venise, il faut cependant mettre en lumière la désorientation qui frappait les exilés, éprouvés par un voyage long et fatigant. Ils sont nombreux à ne pas 
communiquer leur lieu de destination $»^{51}$. Et l'auteur de citer ces émigrés arrivant souvent de Suisse et qui se disaient «incertains » sur leur futur, s'en remettant «à la Providence " ou débarquant à Brescia «sans savoir ce qu'il en sera de nous, comptant nous arrêter à Brescia si cela nous est consenti, ou sinon aller à Venise en quête de subsistance». L'espérance de ces ecclésiastiques, négociants ou nobles "était de pouvoir rester dans l'État vénitien duquel - ajoute Bazzani - ils attendaient libre circulation et tutelle $»^{52}$.

Arrivé à ce point de la démonstration, il est indispensable de s'interroger sur d'autres Français venus en Italie pendant la même période en vivant une condition diamétralement opposée à celle des émigrés. En effet, les agents envoyés de France par la Convention, par le Directoire ou par Napoléon vécurent eux aussi des formes de dépaysement qui dépassaient le sentiment du pittoresque : conscients d'un décalage moral, ils observaient la péninsule tantôt avec l'humilité du bâtisseur qui sait l'immensité de la tâche à accomplir, tantôt en se laissant habiter par un complexe de supériorité. Entre les militaires, simples soldats ou officiers, les commissaires du gouvernement français envoyés en mission, les savants ou gens de lettres en tournées d'inspection, les diplomates, les ingénieurs et bientôt les préfets en poste pour une durée qu'ils ne connaissaient pas, la manière de se sentir étrangers varia considérablement.

29 À l'esprit de conquête militaire put correspondre chez ces Français la logique de l'enquêteur observateur, comme une revanche sur l'impossible domination à laquelle la France n'avait cessé de prétendre depuis les guerres d'Italie. L'objectif était dès lors de s'approprier l'Italie. Les préliminaires au Voyage en Hollande de Diderot ou le Voyageur naturaliste de Lettsom ${ }^{53}$, puis l'Essai de Berchtold, paru en anglais en $1789^{54}$, offraient aux successeurs des voyageurs du Grand Tour devenus soldats ou administrateurs la possibilité de mettre leur venue en Italie au service non plus de la formation personnelle, mais du «bien» de l'humanité. L'enquêteur administrateur s'inscrivait par-là dans une tradition que l'époque révolutionnaire renouvela avec les Questions de statistique de Volney, rédigées en 1795, soit deux ans avant la traduction en français de l'Essai de Berchtold ${ }^{55}$. Grâce à la technique d'investigation prônée par Volney, le Français armé de son statut de citoyen agent du pouvoir français resta sans doute un étranger en Italie, mais put s'y comporter comme voyageant avec profit au service de la France. Or, ce type de voyageur administrateur qui savait l'art de collecter les informations ${ }^{56}$ se détache résolument du modèle des Français du Grand Tour désireux de s'instruire en se divertissant et ne rejoint pas davantage les émigrés errant d'une ville à l'autre. Présent dans l'Italie du triennio ou de la décennie napoléonienne, il exprime une conscience de soi de la nation républicaine qui fait contraste avec le « cadavre » de l'Italie que Monge décrit à Rome après le traité de Tolentino : « Rome est humiliée, appauvrie, sa puissance est diminuée [...] D'ailleurs ce vieux cadavre n'a plus qu'un souffle de vie ${ }^{57}$. Le secrétaire de légation à Parme et bientôt sous-préfet d'Autun Creuzé de Lesser exprime la même condescendance, fruit d'un regard extérieur, quand il s'exclame dans la relation publiée en 1806 de son voyage à Naples quatre ans plus tôt :

L'Europe finit à Naples, et même elle y finit assez mal. La Calabre, la Sicile, tout le reste est de l'Afrique. Dans la Sicile, par exemple, on ne trouve presque aucune des aisances de la vie, presque aucune trace de la civilisation. [...] Quant aux chemins, c'est en cela sur-tout que triomphe la barbarie de l'Afrique. Hors les environs de Palerme, il ne faut guere songer à aller en voiture dans la Sicile. Il n'y a de chemins que pour les mulets; et quels chemins ${ }^{58}$ ! 
Terre à la fois étrangère et proche, l'Italie dans son ensemble et a fortiori le Sud devinrent pour ces Français le territoire de l'autre, face auquel les étrangers qu'ils étaient se plaçaient du côté du civilisé, du raisonnable. Depuis la campagne d'Italie de 1796, une distance paradoxale s'était ainsi creusée entre les Italiens et les Français: perturbées par la rencontre entre la guerre, qui fit des seconds une nation conquérante, et la solidarité entre républicains de part et d'autre des Alpes, les catégories de l'étrangeté furent repensées. Chateaubriand force donc le trait lorsqu'il célèbre dans le compte rendu de son voyage de 1803 à Milan l'osmose entre l'habitant italien et le soldat français :

Nous sommes de singuliers ennemis : on nous trouve d'abord insolents, un peu trop gais, trop remuants, nous n'avons pas plutôt tourné les talons qu'on nous regrette. Vif, spirituel, intelligent, le soldat français se mêle aux occupations de l'habitant chez lequel il est logé59.

31 Les voyageurs français de l'époque discutèrent de cette distance et se demandèrent en fait ce qui amenait Français et Italiens, Lombards notamment, à se considérer si étrangers les uns par rapport aux autres. Dès mai 1796, Marmont écrivait dans une lettre annexée à ses Mémoires: "Milan est une très-belle ville, très-grande, trèspeuplée. Ses habitants aiment les Français à la folie ${ }^{60} »$. Et Musset-Pathay, le père d'Alfred, estimait en 1800 que " les Français sont à Milan un peu plus aimés [...] que dans le reste de l'Italie ${ }^{61} »$. Mais c'était pour ajouter qu'en général ils n'étaient pas aimés et même qu'«il existait avant notre révolution, je crois, une antipathie contre nous en Italie ${ }^{62} »$. Le jeu de la conquête et de la possession ne fit que durcir cet héritage. L'orgueil des Français en fit des prédateurs, se nourrissant des richesses des autres. Le pillage des œuvres d'art provoqua l'amertume des habitants vis-à-vis de personnes qui n'étaient plus de simples et bienveillants visiteurs de passage, mais à de nombreux égards des envahisseurs venus de l'autre côté des Alpes.

Pourtant notre recherche sur le sentiment d'étrangeté que les Français éprouvèrent en Italie nous amène à considérer une autre facette de cette catégorie mouvante qu'est l'étranger, propre à saisir un autre type de nostalgie que celle de l'émigré : la nostalgie de l'agent du pouvoir français. Poussant vers une autre direction que les enquêtes menées par Michael Broers sur l'attitude «coloniale» des Français dans l'Italie dominée par la France napoléonienne ${ }^{63}$, Aurélien Lignereux a souligné combien fut rude l'épreuve du dépaysement pour les "Impériaux", ces quelques centaines de fonctionnaires que Paris envoya dans les divers départements du Grand Empire, les obligeant à s'installer loin de chez eux et les amenant parfois à s'insérer, voire à s'enraciner dans une terre qui demeurait étrangère malgré le lien politique et administratif avec la France ${ }^{64}$. Chez ces citoyens envoyés par Paris en Italie, ingénieurs ou militaires, la nostalgie de la mère patrie se manifesta par une voie symétrique, mais opposée à celle des émigrés errant d'une ville à l'autre. Ces administrateurs étaient obligés de résider pour un nombre d'années qu'au départ ils ne connaissaient pas dans une terre inconnue, fût-elle, comme Florence, célébrée par les voyageurs du Grand Tour: le sentiment d'isolement éprouvé par ces ingénieurs stationnés dans l'Italie napoléonienne les rendait terriblement malheureux parce qu'ils étaient éloignés de leur région d'origine en France. Leurs demandes de réintégration "dans l'intérieur ", au "centre de la France ", dans le "pays natal ", là où se trouvaient les objets de leurs affections, prouvaient qu'ils n'avaient de cesse d'y retourner. L'Italie était bien pour eux une terre étrangère qu'ils rêvaient de quitter pour rentrer chez eux : «À quoi me menerait une plus longue résidence dans ce pays lointain, s'exclame depuis Florence, 
en 1810, l'ingénieur en chef Guillaume Goury (1768-1854), natif de Landerneau, si ce n'est à la plus désagréable et à la plus fatiguante (sic) des inspections, sans aucun avantage $?{ }^{65}$.

33 En ces temps troublés de la Révolution et de l'époque napoléonienne, de nombreux Français, émigrés ou patriotes, réagirent ainsi à la stigmatisation dont ils avaient été la cible en érigeant de nouvelles barrières. Certains rentrèrent chez eux en dissimulant leur identité, à l'instar de Chateaubriand en 1800 : « Je me glissai dans ma patrie à l'abri d'un nom étranger : caché doublement dans l'obscurité du Suisse Lassagne et dans la mienne, j'abordai la France avec le siècle ${ }^{66}$ ». Après avoir tenté leur chance, éprouvé les pesanteurs de l'éloignement ou subi les humiliations d'administrations étrangères, ceux qui revinrent en France sous le Consulat ou à la fin de l'Empire notèrent une différence profonde avec le monde connu antérieurement. Nostalgiques de la grandeur impériale, les "Impériaux » eurent du mal à trouver leur place dans la France de la Restauration ${ }^{67}$. Quant aux émigrés, ils étaient devenus étrangers vis-à-vis de la France en émigrant : « $O$ mes pénates ! vous avouerai-je le bonheur que j'éprouvai en perdant de vue ce clocher qui s'élève au-dessus des cendres de mes pères ", se remémore Marcillac en songeant à sa fuite de mars $1791^{68}$. Dix ans plus tard, le plaisir du retour augmenta toutefois l'attachement à cette terre :

Combien j'étais éloigné de concevoir le plaisir que j'éprouvai dix années après cette époque funeste, en revoyant vos ruines seulement; en traversant furtivement, et avec crainte d'être reconnu de quelques vieux vassaux, le domaine de mes pères morcelé et devenu la propriété de ces mêmes paysans qui s'armaient volontairement, en 1789 , pour défendre leur seigneur qu'ils appelaient aussi leur père ${ }^{69}$.

34 Faisant retour sur une identité en apparence reniée, les émigrés devenaient français comme ils ne l'avaient jamais été jusque-là : c'est ainsi que Fernand Baldensperger a montré voici près d'un siècle comment les expériences d'exil à l'étranger avaient contribué à l'enrichissement de leur moi et à la révélation d'un attachement jusque-là inconnu pour leur patrie d'origine ${ }^{70}$. Il est difficile de dire si ce processus était à l'œuvre dès les débuts de la Révolution. On le relève dans un récit où le comte Félix de Romain oppose à la beauté de Rome les restes archéologiques de sa région d'origine, Angers, qu'il juge suffisants pour se faire une idée réelle et profonde de l'Antiquité, sans avoir besoin de se rendre en Italie :

Ils ont tant d'orgueil de leurs richesses, dans toute cette Italie, qu'ils feroient croire que nous n'avons rien en France. Je me dispute tous les jours avec eux, leur soutenant que nous avons beaucoup de fort belles villes qui renferment de trèsbelles choses ; que nous possédons aussi des antiquités et des ruines romaines, et en somme, notre patrie offre tant de variétés, que le voyage de France seroit trèsintéressant à faire pour un Italien, et aussi curieux que celui d'Italie, si on excepte les monumens de l'ancienne Rome, les phénomènes de Naples, et la singularité de Venise $^{71}$.

Mais si le voyage en Italie qui est ici narré remonte à 1788-1789, sa parution date du milieu des années 1820, sous la Restauration. En revanche, le même réflexe patriotique, lié à une forme de refoulement de l'étranger, se manifeste dès 1791 dans ces lignes du marquis de Pons au retour d'Italie alors qu'il fait étape à Nevers :

Le 24 je partis de Moulins apres sept heures[,] allai diner à Nevers a l'auberge pres le College ou on est tres bien et allai coucher a Cosne au Grand Cerf ou on est a merveille. J'y fus obsedé comme c'est d'usage par les marchandes de ciseaux et de gands (sic); j'y achetai d'une $\mathrm{M}^{\text {de }}$ Camus des bas de peau pour la campagne qui 
étoient beaucoup mieux faits que ceux tant vantés de Vicence et de Verone et qu'elle ne me vendit que 40 sols la grande ${ }^{72}$. mieux reconnaitre la valeur des productions locales : le noble en voyage achetait des souvenirs ou objets utiles caractéristiques de la région qu'il traversait, comme à Nevers. Alors que l'Italie avait jusque-là profité de l'attrait dont se parait tout ce qui venait de l'étranger, Pons nous dit qu'on pouvait trouver chez soi des produits tout à fait équivalents, voire meilleurs. Cela prouve qu'un certain patriotisme gagna la noblesse. Dans ce déclassement de la valeur attribuée aux objets vus à l'étranger par rapport à ceux qui étaient à portée de main, le noble revêtait presque à son insu les habits du patriote, rompait dès le début de la Révolution avec le cosmopolitisme et, dans sa méfiance vis-à-vis de l'étranger, rejoignait peut-être, quoique de façon partielle, un peu de la fierté des «Impériaux ».

\section{Conclusion}

Certes le fossé s'accrut à l'époque révolutionnaire entre des États dont les habitants, quelle que fut la durée de leur voyage, manifestaient juridiquement leur condition d'étranger lorsqu'ils franchissaient des frontières mieux délimitées en raison de traités comme celui de Turin en 1760 entre les royaumes de France et de Sardaigne. Les procédures de contrôle à l'entrée dans les États ou au passage dans les villes contribuèrent à rendre plus visible un statut qui jusque-là disait la soumission à un souverain, façonnant des identités qui désormais distinguaient l'ensemble des citoyens d'une nation de ceux des nations voisines. Cette requalification des étrangers n'empêchait pas de les accueillir quand ils ne représentaient pas une menace pour l'ordre institué ou contribuaient au maintien de bonnes relations entre la France et les États voisins, italiens en particulier. À l'instar des transferts de compétences qui se pratiquaient sous l'Ancien Régime, ils pouvaient encore dans certains cas contribuer à renforcer l'ordre existant en ouvrant la voie à une rapide intégration dans la communauté d'accueil.

De la fin des années 1780 à l'époque napoléonienne, l'étrangeté éprouvée par les Français partis en Italie se manifesta cependant de multiples façons, ce qui amène à repenser cette catégorie. Étranger fut celui que l'on ne connaissait pas et qui pouvait menacer l'ordre institué dans un État italien par sa seule présence, étranger celui qui, en France même, ne faisait pas partie de la communauté politique définie par les idéaux de la Révolution, étranger celui que les autorités étrangères à la France avaient besoin de classer en désignant sa patrie de provenance et en l'identifiant par une série d'informations précises sur son nom, ses activités, ses buts et les dates de ses déplacements. Ainsi, malgré l'écart séparant l'émigré plus ou moins actif au service de la monarchie, le négociant soucieux de continuer son activité, le curieux cosmopolite héritier du Grand Tour ou l'agent du nouvel État républicain ou impérial, tout Français qui se rendait en Italie portait-il avec lui, entre 1789 et 1815, plus que jamais auparavant, les signes de sa nation par-delà ceux de son métier ou de son groupe social d'appartenance.

Il reste que cet étranger venu de France n'était pas uniquement ce que les administrations en faisaient. Il n'était pas seulement un nom dans la grande machine révolutionnaire ou contre-révolutionnaire, dont la présence hors de France manifestait 
une domination ou bien inquiétait les autorités qui cherchaient à mieux le circonscrire, au point de le traquer et parfois de l'expulser. Ce Français diversement accueilli ne s'inscrivait pas seulement au sein de la longue histoire appelée à départager également en France ceux qui, venant d'ailleurs, auraient droit à l'accueil et ceux que l'on n'accueillerait pas sur le sol national ${ }^{73}$. Il fut aussi ce qu'il disait de lui, devenant étranger par ses hantises et par le sentiment d'éloignement qu'il ressentait, autant en traversant la France comme un proscrit que lorsqu'il était envoyé loin de sa patrie et souffrait de ne pouvoir la regagner. À ce titre, en contrepoint de la logique d'appartenance liée au statut de citoyen, le sentiment d'être étranger a pu devenir un état d'âme, générer une manière de vivre et produire des modes d'appréciation de soi renvoyant à de nouvelles valeurs, moins révolutionnaires ou contre-révolutionnaires que sentimentales. S'adaptant à des positionnements sociaux et politiques de nature aussi opposée que ceux de l'émigré ayant fui la France ou du fonctionnaire la servant à l'étranger, la nostalgie, la peur, la souffrance de l'éloignement de sa patrie et le désir du retour devinrent autant de manières par lesquelles se redéfinirent en temps de révolution les configurations complexes de l'étranger.

\section{NOTES}

1. Leopold BERCHTOLD, An Essay to Direct and Extend the Inquiries of Patriotic Travellers, Londres, chez l'Auteur, 1789 (traduit en français en 1797); Constantin-François de Chassebœuf, comte de volneY, Questions de statistique à l'usage des voyageurs, 1795 (édité dans Euvres complètes de Volney, Paris, Bossange frères, 1821, puis Paris, Parmentier, 1825-1826).

2. Gábor GELLÉRI, Lessons of Travel in Eighteenth-Century France: From Grand Tour to School Trips, Wooddbridge; Rochester, Boydell Press, 2020, p. 208 (c'est nous qui traduisons).

3. Aurélien Lignereux, Les Impériaux. Administrer et habiter l'Europe de Napoléon, Paris, Fayard Histoire, 2019.

4. Sur la citoyenneté d'Ancien Régime et l'apparition d'une nouvelle forme de citoyenneté pendant la Révolution, voir Peter SAHLINS, Unnaturally French : Foreign Citizens in the Old Regime and After, Ithaca, Cornell University Press, 2004 et Raymonde MONNIER (dir.), Citoyens et citoyenneté sous la Révolution française, Paris, Société des Études robespierristes, 2006.

5. Ainsi que le rappelle Sophie WAHNICH dans la postface de L'impossible citoyen. L'étranger dans le discours de la Révolution française, Paris, Albin Michel, 2010 [1997], p. XIV.

6. Sur le cas piémontais voir Simona CERUTTI, Étrangers : étude d'une condition d'incertitude dans une société d'Ancien Régime, Montrouge, Bayard, 2012.

7. Antoine FURETIÈRE, entrées «Estrange" et «Estranger», Dictionnaire universel, La Haye ; Rotterdam, Arnout \& Reinier Leers, 1690, 2 vol.

8. Constitution du 24 juin 1793 (6 messidor an I), article 4, alinéa 2. La durée de domicile continu en France pour prétendre à la citoyenneté avait été fixée à cinq ans dans la Constitution du 3 septembre 1791 (titre II, article 3), puis fut portée à sept ans dans la Constitution de l'an III (titre II, article 10).

9. Rogers BRUBAKER, Citizenship and Nationhood in France and Germany, Cambridge, Harvard University Press, 1992 (trad. franç. 1997) ; Olivier LE COUR GRANDMAISON, Les citoyennetés en 
révolution, 1789-1794, Paris, PUF, 1992 ; Sophie WAHNICH, L'impossible citoyen..., op.cit. ; Michael RAPPORT, Nationality and Citizenship in Revolutionary France. The Treatment of Foreigners, 1789-1799, Oxford, Clarendon Press, 2000.

10. Gilles BERTRAND, «Aux sources du voyage romantique : le voyage patriotique dans la France des années 1760-1820", dans Alain Guyot, Chantal Massol (dir.), Voyager en France au temps du romantisme. Poétique, esthétique, idéologie, Grenoble, ELLUG, 2003, p. 35-53.

11. Jacques SolÉ, « Des voyageurs officiels dans la France profonde au temps de la Terreur », dans Par monts et par vaux. Migrations et voyages, Festival d'histoire de Montbrison, 2001, repris dans De Luther à Taine: essais d'histoire culturelle, Grenoble, PUG, 2011, p. 203-222 ; Jean-Luc CHAPPEY, Sauvagerie et civilisation. Une histoire politique de Victor de l'Aveyron, Paris, Fayard, 2016.

12. Jean BOUTIER, «L'exil: une pratique ordinaire de l'absolutisme? Étienne Baluze à Tours (1710-1713) », dans Fabio Di Giannatale (dir.), Escludere per governare : l'esilio politico fra Medioevo e Risorgimento, Florence, Le Monnier, 2011, p. 114-138.

13. Guillaume MAZEAU, "L'errance républicaine, les Girondins et l'exil intérieur ", dans Gilles Bertrand, Pierre Serna (dir.), La République en voyage, 1770-1830, Rennes, PUR, 2013, p. 149-162.

14. Louis-Marie, marquis de PoNs, Voyage d'Italie, 1790-1791, t. 2, f.207v et $208 \mathrm{r}$ (20 et 22 juillet 1791). Ce manuscrit en deux volumes acquis en 2020 par la Bibliothèque municipale de Grenoble est désormais coté Ms. 4518 (1-2) Rés.

15. Ibid., t. 1, f.9r (20-27 octobre 1790).

16. Louis-Joseph de Bourbon, prince de conDÉ, Journal d'émigration du prince de Condé, 1789-1795, publié par le comte de Ribes, Paris, Georges Servant, 1924, p. 77.

17. Louis-Marie, marquis de Pons, Voyage d'Italie..., op.cit., t. 1, f.4v (17 octobre 1790), 6r (19 octobre 1790).

18. Pierre-Nicolas ANOT, F. MALFILlATRE, Les deux voyageurs, ou Lettres sur la Belgique, la Hollande, l'Allemagne, la Pologne, la Prusse, l'Italie, la Sicile et Malthe [...] depuis 1791 jusqu'à la fin de 1802, Reims, Brigot, [1802], t. 1, p. 236.

19. Ainsi à la Pacaudière, Modane, Lanslebourg, Turin ou Fondi : Louis-Marie, marquis de PONS, Voyage d'Italie..., op.cit., t. 1, f.1v (9 et 10 octobre 1790), 5r (18 octobre 1790), 6r-v (20 octobre $1790)$; t. 2, f.2v (28 avril 1791).

20. Ibid., t. 1, f.25v (9 novembre 1790).

21. Ibid., t. 1, f.34r (16 novembre 1790).

22. Ibid., t. 1, f.5v (19 octobre 1790), 9r (20-27 octobre 1790). Sur le sens de cette expérience du déjà-vu, voir François MOUREAU (dir.), Le second voyage ou Le déjà-vu, Paris, Klincksieck, 1996.

23. Louis de MARCILLAC, Souvenirs de l'émigration, à l'usage de l'époque actuelle, Paris, Baudouin frères, 1825, p. 7.

24. Baron de VITROLLES, Souvenirs autobiographiques d'un émigré, Paris, Émile-Paul frères, 1924, p. 81.

25. Louis-Marie, marquis de Pons, Voyage d'Italie..., op. cit., t. 1, f.3r-v (14 et 15 octobre 1790).

26. Vincent DENIS, Une histoire de l'identité : France, 1715-1815, Seyssel, Champ Vallon, 2008 ; Carlo MANGIO, La polizia toscana: organizzazione e criteri d'intervento, Milan, Giuffrè, 1988; Alfredo VIGGIANO, "Carte d'identità nella Venezia austriaca (1799-1804)», dans Stefano Levati, Livio Antonielli (dir.), Controllare il territorio : norme, corpi e conflitti tra Medioevo e prima guerra mondiale, Soveria Mannelli, Rubbettino, 2013, p. 363-378; ID., "Individuare e classificare. Passaporti concessi e negati nella Venezia austriaca del primo Ottocento", dans Livio Antonielli (dir.), Procedure, metodi, strumenti per l'identificazione delle persone e per il controllo del territorio, Soveria Mannelli, Rubbettino, 2014, p. 105-131.

27. Archivio di Stato di Venezia (ASVe), Inquisitori di Stato 581, 26 janvier-9 février 1795.

28. Traduit de l'italien à partir de l'article de Valentina DAL CIN, "Alla ricerca di un asilo: gli emigrati francesi a Venezia durante la Rivoluzione », dans Gilles Bertrand, Catherine Brice, Mario 
Infelise (dir.), Exil, asile: du droit aux pratiques, $X V I^{e}-X I X^{e}$ siècle, Rome, École française de Rome, à paraître. Sur le premier point de cette argumentation, Dal Cin se réfère à Hannah CALLAWAY, «Revolutionizing property: the confiscation of émigré wealth in Paris and the problem of property in the French Revolution ", thèse de doctorat, Harvard University, Cambridge, Massachusetts, 2015, p. 75-76.

29. Patrick WEIL, Qu'est-ce qu'un Français? Histoire de la nationalité française depuis la Révolution, Paris, Grasset, 2002, p. 16, 23.

30. Gilles BERTRAND, «Reconnaître, classer et contrôler les Français réfugiés à Venise à la fin du XVIII ${ }^{e}$ siècle (1790-1797) ", dans Gilles Bertrand, Catherine Brice, Mario Infelise (dir.), Exil, asile..., op. cit.

31. Archivio di Stato di Torino (ASTo), Segreteria di Stato per gli affari interni del Regno di Sardegna, Serie V - Miscellanea, registri 12 à 14 : « lettere relative agli emigrati (1792-1799)».

32. Archivio di Stato di Torino (ASTo), Materie politiche rapporto all'interno in generale, mazzo $2, \mathrm{~N}$. 7, «1792-1798. Note Generale des Français auxquels on a accordée (sic) la permission de rester dans les Etats du Roi ». Pour un premier aperçu sur ce dossier, voir Gilles BERTRAND, « L'accueil des émigrés français en Piémont en 1792, entre volonté de faire face à l'afflux des Français et prise en compte de la diversité des cas », Studi piemontesi, vol. L, fasc. 2, décembre 2021, p. 387-402.

33. Gilles MONTÈGRE, «Les représentations du contrôle de l'étranger dans les écrits des voyageurs en Italie au XVIII siècle", dans Marco Meriggi, Anna Maria Rao (dir.), Stranieri. Controllo, accoglienza e integrazione negli Stati italiani (XVI-XIX secolo), 2020, p. 77-94 (ici p. 87).

34. François de Paule LATAPIE, Éphémérides, $3^{\mathrm{e}}$ cahier, journée du 4 mars 1775, archives privées de la famille Latapie (cité par G. MONTÈGRE, «Les représentations du contrôle de l'étranger ", contribution citée, p. 92).

35. Marco MERIGGI, «Come procurarsi un passaporto. Il caso di Napoli a metà Settecento », dans Claudia Moatti, Wolfgang Kaiser (dir.), Gens de passage en Méditerranée de l'Antiquité à l'époque moderne. Procédures de contrôle et d'identification, Aix et Paris, MMSH et Maisonneuve \& Larose, 2007, p. 399-412.

36. Benjamin Constant écrit, commentant son équipée de 1787 en Angleterre : «Je n'avais point de passeport, mais dans cet heureux temps, il n'y avait point toutes les difficultés dont chaque démarche a été hérissée, depuis que les Français, en essayant d'être libres, ont établi l'esclavage chez eux et chez les autres ", Cahier rouge, cité par Jean WAQUET, « Voyage de terre et passeport en France de la fin de l'Ancien Régime à 1870 ", Mémoires de la Société d'Histoire et d'Archéologie de Bretagne, t. LXI, 1984, p. 199-230, ici p. 203.

37. Louis-Marie, marquis de PoNS, Voyage d'Italie..., op. cit., t. 1, f.3r (14 octobre 1790). Jean-Louis Emmery fut président de l'Assemblée nationale du 25 septembre 1790 au 8 octobre 1790 et à nouveau du 4 janvier 1791 au 17 janvier 1791. Le récit de Pons ne cesse de mentionner des lettres de recommandation tout au long du voyage.

38. Ibid., t. 2, f.206v-207r (17-20 juillet 1791).

39. Voir par exemple Joseph TURQUAN, Les femmes de l'émigration, 1789-1815. Deuxième série, Angleterre-Italie-Russie-Autriche-Espagne-Amérique-retour en France, Paris, Émile-Paul, 1912, p. 273-276.

40. Marc de BOMBELLES, Journal, t. 3, 1789-1792, éd. Jean Grassion et Frans Durif, Genève, Droz, 1993, p. 233.

41. Pierre-Nicolas ANOT, F. MALfillatRe, Les deux voyageurs..., op. cit., t. 1, p. 265 et 285.

42. Roberto ZAUGG, Stranieri di antico regime: mercanti, giudici e consoli nella Napoli del Settecento, Rome, Viella, 2011 ; Diego CARNEVALE, «Andata e ritorno. La mobilità delle persone nel Regno di Napoli : procedure e dinamiche nel Settecento », dans Marco Meriggi, Anna Maria Rao (dir.), Stranieri..., op. cit., p. 117-136. 
43. Gilles BERTRAND, «L'administration vénitienne et l'évolution des techniques d'enregistrement des étrangers dans le contexte de la Révolution française (1789-1797) », Diasporas, $n^{\circ} 29,2017$, p. 105-129, https://journals.openedition.org/diasporas/778; ID., «Venise, Florence, deux stratégies différentes pour contrôler les mobilités dans la seconde moitié du XVIII ${ }^{\mathrm{e}}$ siècle ? ", dans Marco Meriggi, Anna Maria Rao (dir.), Stranieri..., op. cit., p. 95-116.

44. Domenico MAIONE, "Mobilité et citoyenneté pendant le Triennio républicain (1796-1799)", thèse de doctorat, université de Naples-Federico II et université Grenoble-Alpes, d'où il a tiré la contribution " "Uno spettacolo compassionevole": il trattamento riservato agli ecclesiastici stranieri durante la Repubblica romana del 1798-99 », dans Marco Meriggi, Anna Maria Rao (dir.), Stranieri..., op. cit., p. 137-159.

45. Voir sur ce point Philippe BOURDIN (dir.), Les noblesses françaises dans l'Europe de la Révolution, Rennes ; Clermont-Ferrand, PUR ; Presses universitaires Blaise-Pascal, 2010 ; Gilles BERTRAND, « Le cosmopolitisme à l'épreuve de la Révolution française. Pratiques aristocratiques et bouleversements des idéaux chez les voyageurs émigrés français en Italie », dans Robert Chagny (dir.), La Révolution française : idéaux, singularités, influences, Grenoble, PUG, 2002, p. 101-114.

46. Amandine FAUCHON CHARDON, «L'émigré Joseph Labrosse, alias Albert-François de Moré, comte de Pontgibaud, et ses réseaux nobiliaires, diplomatiques, financiers et marchands à Trieste ", site $\mathrm{du}$ LUHCIE, https://luhcie.univ-grenoble-alpes.fr/publications-travaux/emigration-exil-etinnovation/; ID., "Réseaux familiaux et construction identitaire d'une noblesse d'épée: l'exemple de l'émigré Albert-François de Moré », dans Philippe Bourdin(dir.), Les noblesses françaises..., op. cit., p. 397-411.

47. Ces citations, tirées de la correspondance conservée au château de Crolles, ont été commentées par Gilles BERTRAND, « Le diplomate, les voyageurs et les émigrés. L'observatoire de la correspondance Bernis-Flavigny dans l'histoire des mobilités culturelles sous la Révolution ", dans Gilles Montègre (dir.), Le cardinal de Bernis. Le pouvoir de l'amitié, Paris, Tallandier, 2019, p. 665-688.

48. Marc de Bombelles, Journal, t. 3, 1789-1792, op. cit., p. 222 (30 avril 1791), 230 (15 mai 1791), 231 (15 et 17 mai 1791).

49. Ibid., t. 3, p. 1 (8 août 1789).

50. Correspondance du marquis et de la marquise de Raigecourt avec le marquis et la marquise de Bombelles pendant l'émigration, 1790-1800, Paris, au siège de la Société, 1892, p. 3 (8 octobre 1790), 5 (22 octobre 1790), 10 (13 novembre 1790).

51. Carlo BAZZANI, Tra dissenso e rivoluzione : Brescia dalla Repubblica di Venezia alla Repubblica italiana (1791-1802), thèse de doctorat, université de Gênes et université Grenoble Alpes, 2021, vol.1, p. 100. L'étude s'appuie ici sur ASVe, Inquisitori di Stato, b. 771 et 772 (notamment f.42r, 12 novembre 1794).

52. Ibid.

53. Denis DIDEROT, « Des moyens de voyager utilement », Préliminaire au Voyage en Hollande et dans les Pays-Bas autrichiens, dans Supplément aux cuvres de Diderot, Paris, Belin, 1818 (écrit en 1774); John Coakley LETTSOM, Le voyageur naturaliste, ou instructions sur les moyens de ramasser les objets d'histoire naturelle, \& de les bien conserver, Amsterdam ; Paris, Lacombe, 1775.

54. Leopold BERCHTOLD, An Essay to Direct..., op. cit.; paru en français sous le titre Essai pour diriger et étendre les recherches des voyageurs qui se proposent l'utilité de leur patrie, Paris, Du Pont, an V-1797.

55. Constantin-François de Chassebœuf, comte de VOLNEY, Questions de statistique..., op. cit.

56. ID., dans CEuvres complètes..., op. cit., éd. 1825-1826, t. VII, p. 377-379.

57. Gaspard MONGE, Correspondance depuis l'Italie, 9 juin 1796-26 mai 1798 (préparée par René Taton, mais non-publiée), lettre à sa femme, de Rome, le 23 février 1797.

58. Auguste CREUZÉ DE LESSER, Voyage en Italie et en Sicile, fait en 1801 et 1802, Paris, de l'Imprimerie de P. Didot l'ainé, 1806, p. 96. L'auteur semble être allé jusqu'à Paestum, mais c'est en bateau qu'il se 
rendit de Naples à Palerme, sans passer donc par la Calabre. Sur les préjugés à l'égard du Sud, y compris depuis le nord de la péninsule, voir Antonino DE FRANCESCO, La palla al piede. Una storia del pregiudizio antimeridionale, Milan, Feltrinelli, 2012, en part. p. 27-47.

59. François-René de CHATEAUBRIAND, Mémoires d'outre-tombe, livre XIV, chap. 7, Paris, Gallimard, coll. « Pléiade », 1951, t. 1, p. 498.

60. Auguste marmont, Mémoires du duc de Raguse de 1792 à 1832, Paris, Perrotin, 1857, t. 1, p. 322 (lettre à son père, 15 mai 1796).

61. Victor-Donatien de MUSSET-PATHAY, Voyage en Suisse et en Italie, fait avec l'armée de réserve, Paris, Moutardier, an XII-1802, p. 148.

62. Ibid.

63. Michael BROERS, The Napoleonic Empire in Italy 1796-1814: Cultural Imperialism in a European Context?, New York, Palgrave Macmillan, 2005.

64. Aurélien LIGNEREuX, Les Impériaux..., op. cit., notamment le chap. 3, intitulé «À l'épreuve du dépaysement ", p. 139-195.

65. Guillaume GOURY, Lettre du 12 avril 1810 au Directeur général des Ponts et chaussées, Paris, Archives nationales (AN), F-14-2237.

66. François-René de CHATEAUBRIAND, Mémoires d'outre-tombe..., op. cit., t. 1, p. 431.

67. Aurélien L IGNEREUX, Les Impériaux..., op.cit., troisième partie intitulée "Une mémoire impériale », p. 255-366.

68. Louis de MARCILLAC, Souvenirs de l'émigration..., op. cit., p. 6.

69. Ibid., p. 6-7.

70. Fernand BALDENSPERGER, Le mouvement des idées dans l'émigration française, Paris, Plon-Nourrit, 2 vol., 1925.

71. Félix de ROMAIN, Souvenirs d'un officier royaliste, contenant son entrée au service, ses voyages en Corse et en Italie, ses campagnes à l'armée de Condé, et celle de 1815, dans la Vendée, par M. de R., Paris, A. Egron, vol. 1, 1824, p. 336.

72. Louis-Marie, marquis de Pons, Voyage d'Italie..., op. cit., t. 2, f.208r-v (24 juillet 1791).

73. Voir à ce sujet Patrick WEIL, Qu'est-ce qu'un Français ?..., op. cit. ; Gérard NOIRIEL, Réfugiés et sanspapiers : la République face au droit d'asile, XIX ${ }^{e}-\mathrm{XX}{ }^{e}$ siècle, Paris, Pluriel, 2012 [1998].

\section{RÉSUMÉS}

Le statut d'étranger renvoie depuis l'âge classique au fait d'être né dans une autre nation, et l'étrangeté à ce qui n'est pas connu ou familier. Avec les contraintes et réglementations de la période révolutionnaire, un triple renversement s'opère pour les Français en voyage, comme on le voit ici dans le cas de l'Italie. À la liberté d'aller et venir et à la recherche du pittoresque des classes les plus riches dans l'Europe cosmopolite succède un dépaysement qui peut amener celui qui n'adhère pas à la citoyenneté à se sentir étranger dans sa propre patrie. Le développement des modes de surveillance en Europe contribue surtout à faire du Français un étranger paradoxal : tantôt accueilli et protégé, tantôt subi, et tantôt craint au point d'être expulsé. Les pratiques de l'enquête, de la domination ou de l'exil, devenues ordinaires pour les Français hors de chez eux, accroissent ainsi le rejet de l'autre autant qu'elles finissent par nourrir des souffrances intimes. Il en résulte des manières nouvelles d'appréhender l'altérité. 
Since the classical age, the status of foreigner has referred to being born in another nation, and strangeness to what is not known or familiar. With the constraints and regulations of the revolutionary period, a threefold reversal took place for French travelers, as we will see here with the case of Italy. The freedom to come and go and the search for the picturesque of the wealthier classes in cosmopolitan Europe was followed by a disorientation that could make those who did not adhere to citizenship feel like strangers in their own country. The development of surveillance methods in Europe contributes above all to making the French person a paradoxical foreigner: sometimes welcomed and protected, sometimes suffered, and sometimes feared to the point of being expelled. The practices of investigation, domination or exile that have become commonplace for French people outside their own country thus increase the rejection of the other as much as they end up feeding intimate suffering. The result is new ways of understanding otherness.

INDEX

Mots-clés : Altérité, Dépaysement, Étrangeté, Nation, Voyage

Keywords : Otherness, Change of scenery, Strangeness, Nation, Travel

\section{AUTEUR}

\section{GILLES BERTRAND}

Université Grenoble Alpes, LUHCIE 